\title{
Massive sialadenitis resulting in critical airway after elective craniotomy: case report
}

\author{
Aditya Vedantam, MD, ${ }^{1,2}$ Daniel Hansen, MD,, Bradley Daniels, BS, ${ }^{1,2}$ and Sandi Lam, MD ${ }^{1,2}$ \\ 1Department of Neurosurgery, Baylor College of Medicine, and 'Division of Pediatric Neurosurgery, Texas Children's Hospital, \\ Houston, Texas
}

\begin{abstract}
The authors report an unusual case of acute, rapidly progressive, unilateral neck swelling following extubation after elective left anterior temporal lobectomy with amygdalohippocampectomy. Due to severe neck swelling, the patient developed critical airway compromise, brachial plexopathy, and Horner's syndrome. After critical airway management and appropriate rehabilitation, the patient recovered completely and remains seizure free at 1.5 years of follow-up.

This case highlights the importance of early recognition of acute postoperative sialadenitis and the steps needed to prevent serious morbidity and possible mortality from this rare complication.
\end{abstract}

http://thejns.org/doi/abs/10.3171/2016.3.PEDS15621

KEY WORDS sialadenitis; neck edema; airway emergency; pediatric; craniotomy; postoperative; neck swelling; submandibular gland

$\mathrm{S}$ URGICAL safety includes effective perioperative management. Neck swelling is an unusual development in pediatric neurosurgery; it can cause life-threatening airway compromise and other pathophysiology. This case illustrates an approach to the management of acute neck swelling and introduces a review of acute postoperative sialadenitis.

\section{Case Report}

A 16-year-old girl with intractable epilepsy resulting from left mesial temporal sclerosis and cortical dysplasia underwent a routine left anterior temporal lobectomy and a amygdalohippocampectomy. The patient was positioned with a large gel roll under the left side of her torso, with her head suspended in Mayfield pins and rotated $45^{\circ}$ to the left of midline. No preoperative venous access attempt was made of the jugular or subclavian veins. The 5-hour surgery proceeded without significant intraoperative events. Extubation was undertaken at the end of the case, and the patient was brought to the recovery room where, within 30 minutes of arrival, she was conversing with family and tolerating oral fluids. She had no immediate postoperative neurological deficits.
Approximately 50 minutes after arrival in the recovery room, the nurse and parents noted right-sided neck swelling (Fig. 1A). The anesthesia and neurosurgery teams were immediately summoned to the patient's bedside. They observed rapidly progressive swelling. The patient reported no pain but developed the following in rapid succession: hoarseness, right-sided tongue deviation, right-sided Horner's syndrome, and right arm paresthesia and weakness, consistent with brachial plexus compression. Bedside fiber optic laryngoscopy revealed paresis of the right vocal fold and significant fullness along the right pharyngeal wall and at the base of the tongue, compressing the airway. The patient was emergently intubated for airway protection (Fig. 1B). Bedside ultrasound of the neck revealed no hematoma or thrombosis. A noncontrast CT scan of the neck, obtained after securing the patient's airway passage, showed an enlarged right submandibular gland with intraductal dilation (Fig. 2). Additionally, significant edema and mass effect were present, displacing the airway to the left, with concomitant collapse of the internal jugular vein.

The differential diagnosis at the time of discovery was wide-ranging and included acute sialadenitis, lymphatic or vascular obstruction, acquired/hereditary angioedema, 


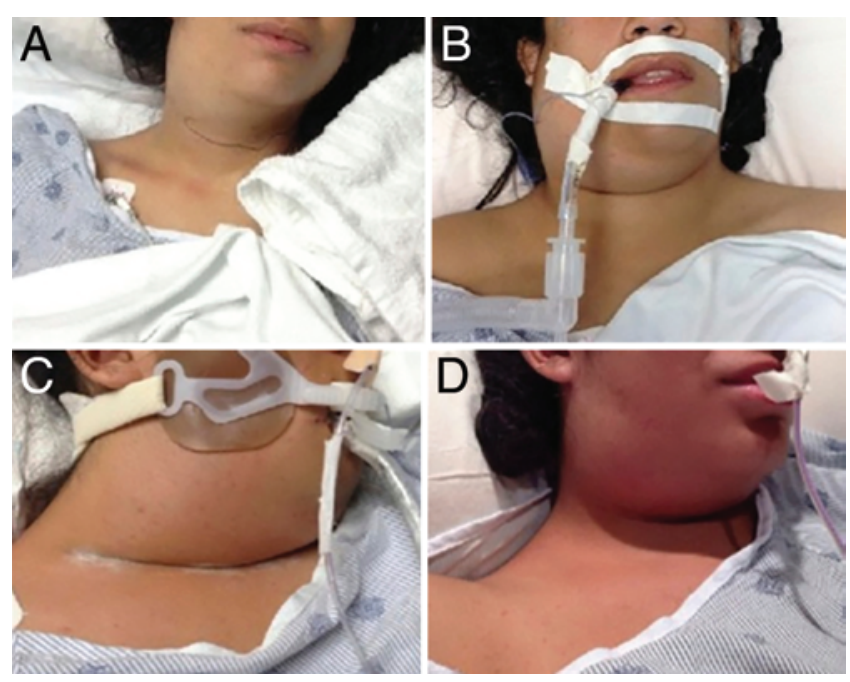

FIG. 1. A: Clinical image showing the patient immediate postoperative in recovery, after swelling was first noticed. B: Increased right submandibular swelling after emergency intubation, 1-2 hours later. C: Peak edema on postoperative Day 7 crossing the midline with extension into the mediastinum and posterior neck. D: Reduced right submandibular edema on postoperative Day 14.

or rhabdomyolysis. Multiple teams (otolaryngology, infectious disease, allergy, and rheumatology) were consulted to aid in diagnosis and treatment, which included clindamycin for possible infection, neutral neck position, head elevation, intravenous fluids for possible rhabdomyolysis and dehydration, and warm compresses, as well as dexamethasone and $\mathrm{C} 1$ esterase inhibitor protein to cover for acquired and hereditary angioedema. Over time, the differential diagnosis was narrowed.

Routine postoperative MRI of the brain on postoperative Day 1 revealed expected changes at the resection cavity, yet findings were concerning for an ischemic infarct that had developed within the right basal ganglia, contralateral to the resection site but ipsilateral to the swelling (Fig. 3). The signal characteristics were consistent with those of an acute infarct coinciding with the patient's perioperative time interval, though it was not possible to distinguish on imaging between an intraoperative or postoperative event. This finding prompted a cerebral and neck angiograms, which were unremarkable. Additional workup for the ischemic infarct, including a hypercoagulable panel, lupus anticoagulant, antiphospholipid panel, lipid panel, erythrocyte sedimentation rate, C-reactive protein, and echocardiogram, was normal. The patient had no neurological deficits on examination. MRI of the neck also demonstrated periglandular edema traversing tissue planes and extending into the right parotid area, without evidence of a focal lesion amenable to drainage or decompression.

Swelling progressed over the next 6 days to involve the mediastinum, crossing the midline, into the posterior side of the neck and upper back, evidenced on imaging and physical examination (Fig. 1). Care remained supportive with continued airway protection. By Day 7, the edema began to subside, and on Day 9, the patient was extubated

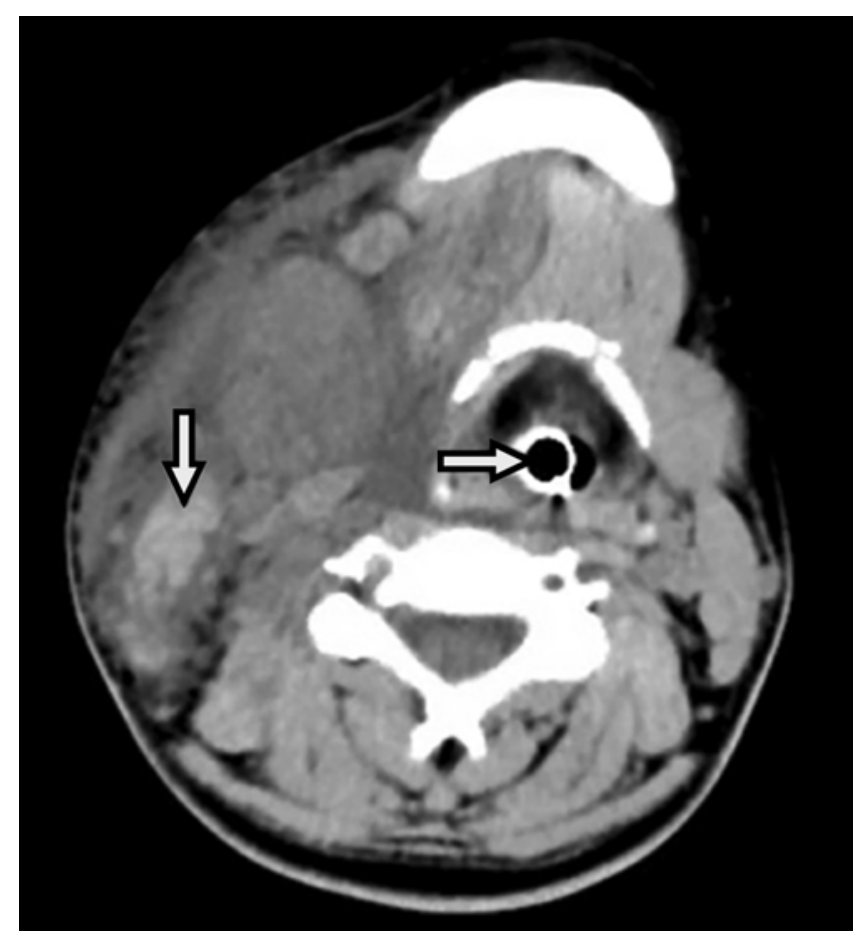

FIG. 2. Axial noncontrast CT scan obtained immediately after surgery demonstrating enlargement of the right submandibular gland with ductal dilation (vertical arrow), generalized edema within the compartments of the right neck, and displacement of the airway to the left (horizontal arrow).

safely. Her right-sided brachial plexopathy, hoarseness, and dysphagia persisted. On Day 14, the edema had noticeably subsided except for the right submandibular gland, which remained swollen and became tender to palpation (Fig. 1).

Due to continued right vocal cord paresis perioperatively, she underwent laryngoscopy in which the right vocal fold was injected with carboxymethyl cellulose gel for short-term vocal fold augmentation. This aided her swallowing function and speech production. On Day 20 after surgery she was transferred to inpatient rehabilitation and recovered significantly during her 2 -week stay there. The right brachial plexopathy had resolved by the time she was discharged to home, and there was near-complete resolution of neck swelling 4 weeks after surgery (Fig. 4). After discharge, she returned to school and successfully completed the academic year. Her vocal cord function was normal at the 3- and 6-month follow-up visits, and there was no need for further intervention. At the 18-month postoperative follow-up visit, she remained seizure free after having been weaned off her antiepileptic medications 1 year after surgery. A detailed neurological examination revealed no persistent neurological deficits related to her perioperative course.

\section{Discussion}

Postoperative sialadenitis is uncommon after neurosurgical procedures. Its estimated incidence is 1 in 1000-3000 of all surgical cases. It most commonly affects older adults who are malnourished or dehydrated in 

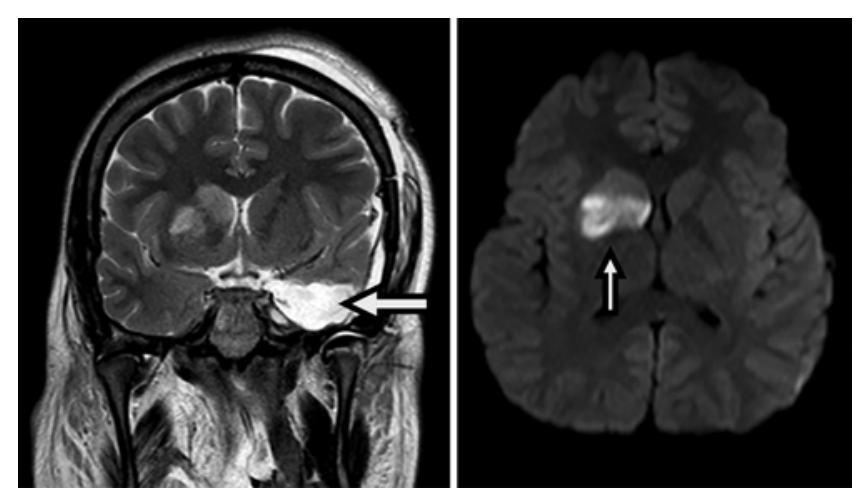

FIG. 3. Left: Coronal T2-weighted MR image obtained on the 1st day after surgery showing expected postoperative changes in the left temporal resection cavity (horizontal arrow) and an acute stroke within the basal ganglia on the right. Right: Diffusion-weighted image showing acute infarction affecting the right caudate, lenticular nucleus, and internal capsule (vertical arrow).

the immediate postoperative period. ${ }^{6}$ Patients typically have a unilateral, firm, nontender swelling in the submandibular area. The involved side is commonly contralateral to the craniotomy site. The swelling often resolves within 5 days and management includes warm compresses, adequate hydration, and sialogogues to facilitate salivation. ${ }^{7}, 10$ Antibiotics can be administered to prevent superimposed bacterial sialadenitis. Corticosteroids are recommended in cases of progressive edema, when there is a high risk for airway compromise. ${ }^{10,11}$

To our knowledge, there have been 3 reported cases of postoperative sialadenitis in pediatric neurosurgical patients: an 8-year-old who underwent occipitoparietal craniotomy for arteriovenous malformation, a 3-year-old who received an auditory brainstem implant, and a 5year-old who underwent temporal lobectomy for cortical dysplasia. ${ }^{8,10,11}$ In 2 patients, the parotid gland was affected primarily, ${ }^{10,11}$ and, although the swelling did not compromise the airway, one patient did develop a transient facial nerve palsy due to pressure effects. ${ }^{10}$ Our patient had involvement of the submandibular gland primarily, which increased the risk of serious airway obstruction in the setting of progressive edema. In all published cases, the swelling was noted only after extubation, on the contralateral side, and was rapidly progressive. Similar to the case described by Munshi et al., our patient developed a critical airway obstruction and needed emergent reintubation. ${ }^{8}$ Use of a fiberoptic scope may be necessary for securing the airway since anatomical landmarks required for an emergency tracheostomy are masked by the overwhelming edema. Local swelling may cause compression effects on adjacent structures such as the brachial plexus, cranial nerves in the neck and face, larynx, trachea, and internal jugular vein. Unique to our case was the development of an ipsilateral ischemic infarct without evidence of arterial vessel compression. No obvious thromboembolic source was identified, and although it seems more than coincidental in its timing, we cannot definitively link our patient's infarct to her postoperative sialadenitis. Neck manipulation during intubation, ${ }^{4}$ or surgical positioning, ${ }^{15}$

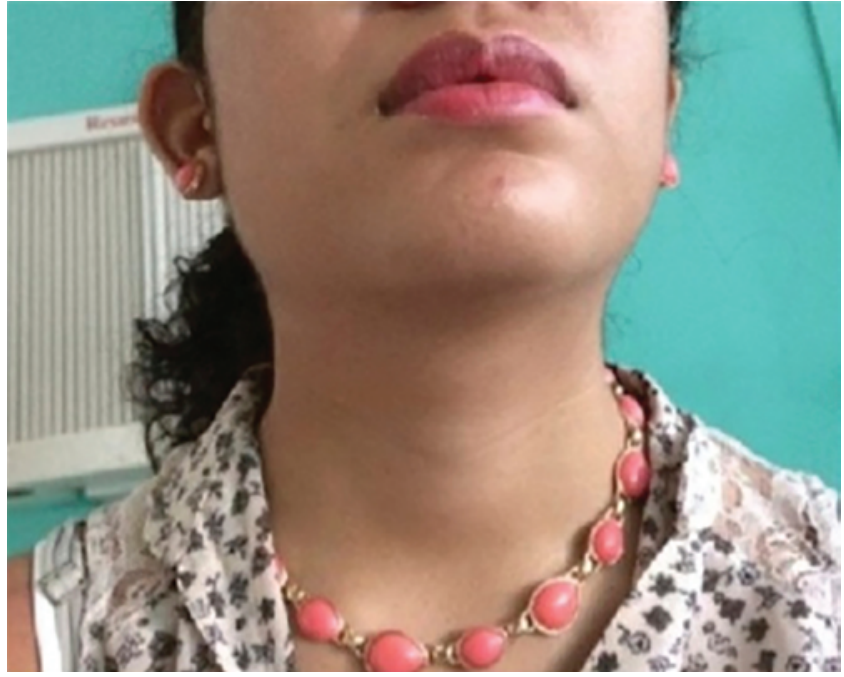

FIG. 4. Near-complete resolution of right submandibular swelling seen at 4 weeks after surgery.

can induce carotid artery dissection. There was no evidence of dissection of the cervical internal carotid artery on angiography. It is theoretically possible that neck positioning during surgery may have caused kinking of the carotid artery that led to thromboembolic strokes. ${ }^{1}$

The etiology of acute sialadenitis in the postoperative period remains uncertain, but intraoperative patient positioning has been postulated as one potential cause. Although our patient was only moderately rotated (Fig. 5), placing a patient's head in any rotated and flexed posture can compress soft tissues in the neck around the gland,

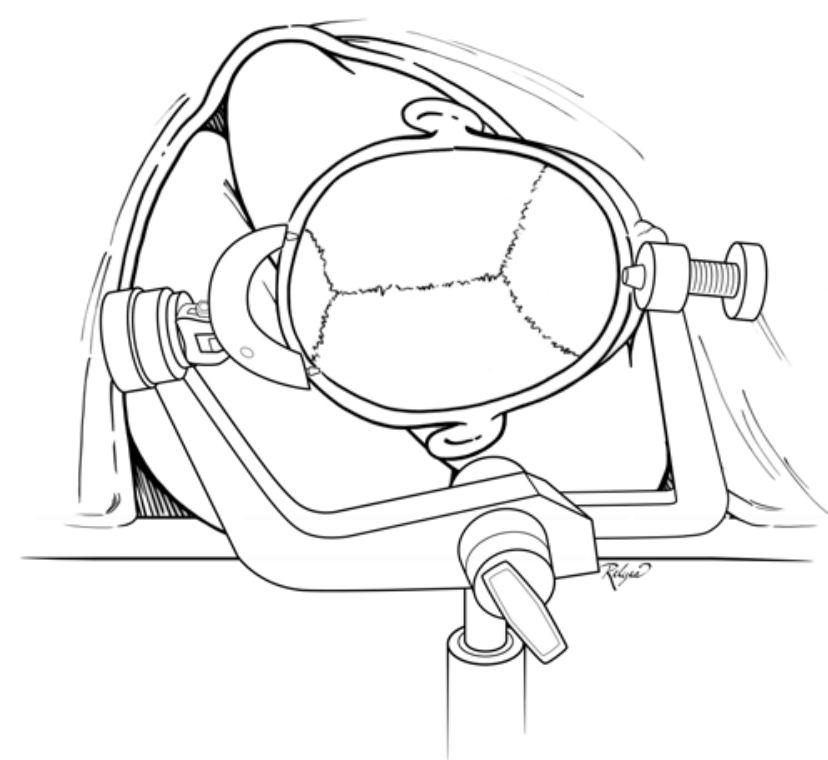

FIG. 5. Patient positioning for this surgery: large gel roll under the left torso to elevate by 45 degrees, head suspended in Mayfield pins and rotated 45 degrees to the right of midline to present the left side of the head. Artist: Kathy Relyea. Copyright Division of Pediatric Neurosurgery, Texas Children's Hospital. Published with permission. 
producing pressure and possible ischemia. The duct of the submandibular gland is also vulnerable to compression due to displacement of the tongue by an endotracheal tube. Obstruction of the duct causes salivary stasis and provides an optimal environment for bacterial infection. ${ }^{5,13}$ In addition to sialadenitis, compression of the contralateral internal jugular vein can obstruct venous return and contribute to facial and neck swelling after neurosurgical procedures., ${ }^{7}$

Previously reported cases of sialadenitis commonly involved patients with operative durations greater than 4 hours, and all involved either flexion or rotation of the neck (Table 1), ${ }^{3,8-14}$ Berker et al. presented a 5-case se- ries of postoperative parotitis, each with surgeries lasting 4-6 hours and completed with the patient in the sitting or semisitting positions for pathologies of the posterior fossa. Three of 5 patients were positioned with head tilt and associated neck flexion. ${ }^{2} \mathrm{Kim}$ et al. published a series of 5 patients with postoperative submandibular sialadenitis who had undergone skull base surgery via a retrosigmoid (in the supine position) and far-lateral (in the park-bench position) approach, with extreme rotation and flexion of the neck. Four of the 5 patients required either continuation of operative intubation or emergency reintubation for airway protection at the end of the case.

Prevention of postoperative sialadenitis should be aid-

TABLE 1. Summary of prior reports on acute postoperative sialadenitis in adult and pediatric patients after neurosurgical procedures

\begin{tabular}{|c|c|c|c|c|c|c|c|}
\hline \multirow[b]{2}{*}{ Authors \& Year } & \multirow[b]{2}{*}{$\begin{array}{l}\text { Age (yrs), } \\
\text { Sex }\end{array}$} & \multicolumn{4}{|c|}{ Surgery-Related Data } & \multicolumn{2}{|c|}{ Outcome } \\
\hline & & Procedure & Patient Position & Head Position & $\begin{array}{l}\text { Duration } \\
\text { of Op }\end{array}$ & $\begin{array}{l}\text { Initial Gland } \\
\text { Involvement }\end{array}$ & Complications \\
\hline \multirow{5}{*}{$\begin{array}{l}\text { Berker et al., } \\
2004\end{array}$} & $33, \mathrm{~F}$ & Resection of It VS & Sitting & Lt tilt & $6 \mathrm{hrs}$ & Rt parotid & \multirow{5}{*}{ None } \\
\hline & $38, \mathrm{M}$ & Resection of It VS & Sitting & Lt tilt & $5 \mathrm{hrs}$ & Rt parotid & \\
\hline & $40, \mathrm{~F}$ & Resection of rt VS & Sitting & Rt tilt & $6 \mathrm{hrs}$ & Lt parotid & \\
\hline & $60, F$ & $\begin{array}{l}\text { Resection of posterior } \\
\text { fossa tumor }\end{array}$ & Sitting & Neutral & $6 \mathrm{hrs}$ & Lt parotid & \\
\hline & $45, F$ & $\begin{array}{l}\text { Resection of parasagittal } \\
\text { meningioma }\end{array}$ & Semisitting & $\begin{array}{l}\text { Neutral, slight } \\
\text { fwd flexion }\end{array}$ & $4 \mathrm{hrs}$ & Rt parotid & \\
\hline \multirow{5}{*}{ Kim et al., 2008} & \multirow{5}{*}{$\begin{array}{l}\text { 20-64 } \\
\text { (mean } \\
\text { age 40): } \\
3 \mathrm{M}, 2 \mathrm{~F}\end{array}$} & Retrosigmoid craniotomy & Supine & \multirow{5}{*}{ CL rotation } & \multirow{5}{*}{$3-6$ hrs } & \multirow{5}{*}{$\begin{array}{l}\text { CL submandibu- } \\
\quad \text { lar }\end{array}$} & \multirow{5}{*}{$\begin{array}{l}\text { Airway compromise } \\
\text { (1 patient) }\end{array}$} \\
\hline & & Retrosigmoid craniotomy & Supine & & & & \\
\hline & & Retrosigmoid craniotomy & Supine & & & & \\
\hline & & Retrosigmoid craniotomy & Supine & & & & \\
\hline & & $\begin{array}{l}\text { Far-lateral suboccipital } \\
\text { craniotomy }\end{array}$ & Park-bench & & & & \\
\hline $\begin{array}{l}\text { Cavaliere et al., } \\
2009\end{array}$ & $73, \mathrm{~F}$ & $\begin{array}{l}\text { Rt occipitoparietal } \\
\text { craniotomy }\end{array}$ & Prone & Rt rotation & $7 \mathrm{hrs}$ & $\begin{array}{l}\text { Lt submandibular } \\
\quad \& \text { parotid }\end{array}$ & $\begin{array}{l}\text { Complete airway } \\
\text { obstruction }\end{array}$ \\
\hline $\begin{array}{l}\text { Munshi et al., } \\
1984\end{array}$ & $8, M$ & $\begin{array}{l}\text { Rt occipitoparietal } \\
\text { craniotomy }\end{array}$ & Sitting & $\begin{array}{l}\text { Fwd flexion, It } \\
\text { rotation }\end{array}$ & $10 \mathrm{hrs}$ & Lt submandibular & Airway compromise \\
\hline $\begin{array}{l}\text { Narayan \& Uma- } \\
\text { maheswara, } \\
1999\end{array}$ & $40, \mathrm{~F}$ & $\begin{array}{l}\text { Rt retromastoid suboc- } \\
\text { cipital craniotomy }\end{array}$ & Lt lateral & $\begin{array}{l}\text { Fwd flexion, It } \\
\text { rotation, It tilt }\end{array}$ & $8 \mathrm{hrs}$ & Lt submandibular & Airway compromise \\
\hline $\begin{array}{l}\text { Özdek et al., } \\
2014\end{array}$ & $3, \mathrm{~F}$ & $\begin{array}{l}\text { Rt retrosigmoid auditory } \\
\text { brainstem implantation }\end{array}$ & Supine & Lt rotation & $5 \mathrm{hrs}$ & $\begin{array}{l}\text { Lt parotid \& sub- } \\
\text { mandibular }\end{array}$ & Lt facial nerve palsy \\
\hline $\begin{array}{l}\text { Rowell et al., } \\
2010\end{array}$ & $5, M$ & $\begin{array}{l}\text { Lt temporal craniotomy \& } \\
\text { It quadriceps biopsy }\end{array}$ & $\begin{array}{l}\text { Supine, then re- } \\
\text { positioned to rt } \\
\text { semirecumbent }\end{array}$ & $\begin{array}{l}\text { Rt lat side on } \\
\text { padded horse- } \\
\text { shoe holder }\end{array}$ & $5.75 \mathrm{hrs}$ & Rt parotid & None \\
\hline $\begin{array}{l}\text { Shimizu et al., } \\
2009\end{array}$ & $56, F$ & $\begin{array}{l}\text { Rt suboccipital crani- } \\
\text { otomy }\end{array}$ & Lt park-bench & $\begin{array}{l}\text { Fwd flexion, It } \\
\text { rotation, It tilt }\end{array}$ & $10 \mathrm{hrs}$ & Lt submandibular & $\begin{array}{l}\text { Lt brachial plexopa- } \\
\text { thy }\end{array}$ \\
\hline $\begin{array}{l}\text { Singha et al., } \\
2009\end{array}$ & $23, F$ & $\begin{array}{l}\text { Rt retromastoid suboc- } \\
\text { cipital craniotomy }\end{array}$ & Extreme It lateral & Lt rotation & $5 \mathrm{hrs}$ & Lt submandibular & Airway compromise \\
\hline Tattersall, 1984 & $30, F$ & $\begin{array}{l}\text { Posterior fossa crani- } \\
\text { otomy }\end{array}$ & Sitting & $\begin{array}{l}\text { Maximum fwd } \\
\text { flexion }\end{array}$ & $12 \mathrm{hrs}$ & $\begin{array}{l}\text { Bilat subman- } \\
\text { dibular }\end{array}$ & $\begin{array}{l}\text { Death by asphyxi- } \\
\text { ation }\end{array}$ \\
\hline Present case & $16, F$ & Lt temporal craniotomy & Supine & Rt rotation & $5 \mathrm{hrs}$ & $\begin{array}{l}\text { Rt submandibu- } \\
\quad \text { lar }\end{array}$ & $\begin{array}{l}\text { Rt brachial plexopa- } \\
\text { thy, airway } \\
\text { compromise, rt } \\
\text { CN XII palsy, rt } \\
\text { ischemic stroke }\end{array}$ \\
\hline
\end{tabular}

$\mathrm{BL}=$ bilateral; $\mathrm{CL}=$ contralateral (relative to craniotomy); $\mathrm{CN}=$ cranial nerve; fwd = forward; $\mathrm{VS}=$ vestibular schwannoma. 
ed by carefully positioning the patient for neurosurgical procedures. Reducing the degree of intraoperative head rotation and flexion may decrease glandular compression and the risk of duct obstruction. Adjustments during patient positioning should be considered to prevent high degrees of head and neck manipulation. Recommendations for anesthesiologists include frequent checks of head position, maintenance of adequate hydration for the patients throughout the procedure, and minimization of the use of anticholinergic, diuretic, and parasympathomimetic (including antiadrenergic) agents. ${ }^{5,11,13}$ Awareness of this potential complication will hopefully aid in its avoidance and lead to swift recognition if it does occur, with subsequent securing of the patient's airway helping to prevent long-term sequelae.

\section{Conclusions}

We describe an unusual case of mass neck swelling following elective craniotomy. This case illustrates the importance of early recognition of acute postoperative sialadenitis and the steps needed to prevent serious morbidity and possible mortality from this rare complication.

\section{References}

1. Bauer R, Sheehan S, Meyer JS: Arteriographic study of cerebrovascular disease. II. Cerebral symptoms due to kinking, tortuosity, and compression of carotid and vertebral arteries in the neck. Arch Neurol 4:119-131, 1961

2. Berker M, Sahin A, Aypar U, Ozgen T: Acute parotitis following sitting position neurosurgical procedures: review of five cases. J Neurosurg Anesthesiol 16:29-31, 2004

3. Cavaliere F, Conti G, Annetta MG, Greco A, Cina A, Proietti R: Massive facial edema and airway obstruction secondary to acute postoperative sialadenitis or "anesthesia mumps": a case report. J Med Case Reports 3:7073, 2009

4. Gould DB, Cunningham K: Internal carotid artery dissection after remote surgery. Iatrogenic complications of anesthesia. Stroke 25:1276-1278, 1994

5. Kim LJ, Klopfenstein JD, Feiz-Erfan I, Zubay GP, Spetzler RF: Postoperative acute sialadenitis after skull base surgery. Skull Base 18:129-134, 2008

6. Krippaehne WW, Hunt TK, Dunphy JE: Acute suppurative parotitis: a study of 161 cases. Ann Surg 156:251-257, 1962

7. Mandel L, Surattanont F: Bilateral parotid swelling: a review. Oral Surg Oral Med Oral Pathol Oral Radiol Endod 93:221-237, 2002
8. Munshi CA, Dhamee MS, Gandhi SK: Postoperative unilateral facial oedema: a complication of acute flexion of the neck. Can Anaesth Soc J 31:197-199, 1984

9. Narayan VB, Umamaheswara GS: Unilateral facial and neck swelling after infratentorial surgery in the lateral position. Anesth Analg 89:1290-1291, 1999

10. Özdek A, Bayır Ö, Işık ME, Tatar EC, Saylam G, Korkmaz $\mathrm{H}$ : Anesthesia mumps resulting in temporary facial nerve paralysis after the auditory brainstem implantation in a 3-yearold child. Int J Pediatr Otorhinolaryngol 78:159-162, 2014

11. Rowell J, Lynn AM, Filardi TZ, Celix J, Ojemann JG: Acute unilateral enlargement of the parotid gland immediately post craniotomy in a pediatric patient: a case report. Childs Nerv Syst 26:1239-1242, 2010

12. Shimizu S, Sato K, Mabuchi I, Utsuki S, Oka H, Kan S, et al: Brachial plexopathy due to massive swelling of the neck associated with craniotomy in the park bench position. Surg Neurol 71:504-509, 2009

13. Singha SK, Chatterjee N: Postoperative sialadenitis following retromastoid suboccipital craniectomy for posterior fossa tumor. J Anesth 23:591-593, 2009

14. Tattersall MP: Massive swelling of the face and tongue. A complication of posterior cranial fossa surgery in the sitting position. Anaesthesia 39:1015-1017, 1984

15. Villalba Martinez G, Navalpotro Gomez I, Serrano Perez L, Gonzalez Ortiz S, Fernández-Candil JL, Steinhauer EG: Surgical position, cause of extracranial internal carotid artery dissection, presenting as Pourfour Du Petit syndrome: case report and literature review. Turk Neurosurg 25:666-669, 2015

\section{Disclosures}

The authors report no conflicts of interest concerning the materials or methods used in this study or the findings specified in this paper.

\section{Author Contributions}

Conception and design: Lam. Acquisition of data: Lam, Vedantam, Daniels. Analysis and interpretation of data: all authors. Drafting the article: Vedantam, Daniels. Critically revising the article: Lam, Hansen. Reviewed submitted version of manuscript: Lam. Administrative/technical/material support: Lam. Study supervision: Lam.

\section{Correspondence}

Sandi Lam, Baylor College of Medicine/Texas Children's Hospital, 6701 Fannin St., CCC Ste. 1230, Houston, TX 77030. email: sklam@texaschildrens.org. 